Original article

\title{
Stunting among Under Five Years Old Children in Rwanda: Influences of Family Planning Status and Household Size and Composition
}

\author{
Jean Bosco Bigirimana $1^{*}$ \\ ${ }^{1}$ College of Medicine and Health Sciences, University of Rwanda, Kigali, Rwanda \\ *Corresponding author: Jean Bosco Bigirimana. College of Medicine and Health Sciences, \\ University of Rwanda, Kigali, Rwanda. Email: geobig1@yahoo.fr.
}

\begin{abstract}
Background

Stunting is one of the main challenges resulting in high child mortality and morbidity thought out the world, especially in many developing countries, including Rwanda. The overall prevalence rate of stunting is estimated at around $38 \%$ of under five years old children in Rwanda.
\end{abstract}

\section{Objective}

To examine the influences of household size and composition and family planning status on stunting among children under five in Rwanda.

\section{Methods}

The current study is a nationally representative cross-sectional study that used the secondary data analysis of Rwanda Demographic and Health Survey (DHS) 20142015. Logistic regression analysis was used to examine the association between family planning and household size and composition.

\section{Results}

The sum-total of children under five in the household $(\log$ odds $=0.373(p<.05)$, $\mathrm{CI}=0.0577,0.689)$, maternal age at childbirth $(\log$ odds $=-0.682(p<.05), \mathrm{CI}=-1.222$, $0.141)$, fertility preference ( $\log$ odds $=-0.296(p<.05), \mathrm{CI}=-0.549,-0.0427)$, and unmet need for family planning ( $\log$ odds $=0.297(p<.05), \mathrm{CI}=0.0193,0.574)$ were statistically significant associated with stunting among studied children.

\section{Conclusion}

The findings of this study suggest a significant association between stunting and family planning and household size and composition.

Rwanda J Med Health Sci 2021;4(1):112-130

Keywords: Child, Rwanda, stunting, Household size and composition, Family planning 


\section{Background}

Undernutrition is one of the main challenges resulting in high child mortality and morbidity thought out the world especially in many developing countries including Rwanda.[1] One of the measures of undernutrition that represents chronic undernutrition is "stunting", characterized by the deceleration or arrest of growth.[2] This is due to long-term insufficient nutrient intake.[3,4] Stunting is a serious problem that impacts negatively cognitive growth, academic achievement and work outcomes in later-life.[5] The World Health Organization (WHO) reported that, globally in 2016, children under five who were affected by stunting account for $22.9 \%$ (154.8 million).[1] Africa was the region wherein stunting among children has increased number, where nearly two in five children are stunted giving an estimation of 59 million stunted children.[1]

The main factor of undernutrition, conceived in previous researches, refers to insufficient food intake in term of quality and quantity.[6-8] The relationship between this condition and the child's nutritional status and child's health, in general, has been operationalized by UNICEF through its conceptual framework for child survival[9].
In Rwanda, regardless of the significant projects to improve new-born and nutrition of the child through both health education and promotion based activities at the health facilities and in the community, and other activities such as to provide one cow per poor family and the program of kitchen garden within each family, among others; yet, throughout the years, intra-household food distribution is still a problem for around $51 \%$ of households[10]. Just $22 \%$ of Rwandan children between one and two years old receive satisfactory nutritious diets[10]. It was evidenced that the process of allocating inner family resources among family members impacts directly the health of the child[11] and consequently affects the productivity of a child when he/she grow up.[9] Besides, in general, big family size is correlated with sub-optimal infant feeding patterns.[12]

The studies revealed that the results of birth order have some variances in individual differences.[6-8] In line with this, undesired pregnancy and child mortality rise with the increased birth order.[8] Certainly, an unwanted pregnancy may be harder for the mother to accept and bond with the child, which could contribute to poorer child outcomes.[3] However, although the link between short birth spacing and preterm birth/small size at birth, and later stunting is 
well studied and documented in Low and Middle-Income Countries like Rwanda,[13] or despite being roughly studied with other determinants, $[3,6-9,14]$ there is no previous study emphasized on the net effect of household size and composition and family planning status on stunting among underfive children in Rwanda, where fertility rate and unmet family planning are still high.[12]

Rwandan children continue to have poor nutritional status as evident with the current overall prevalence rate of stunting (stunting) estimated at around 38\%.[10] However, the nutrition status of children under five can be made better even in the existence of poverty and food insecurity, through the improvement of favourable decisions and behaviours regarding a child's nutrition within the household.[15] This research aims to examine the effects of household size and composition and family planning status on stunting among children under five in Rwanda.

\section{Methods}

\section{Design}

The current study is the secondary data analysis of Rwanda DHS 2014-2015.

\section{Study population and sample size}

The Rwanda DHS 2014-2015 is the only reliable and valid, large, and rich source of data that was available and accessible could better respond to the aim of this study. During RDHS 2014-2015, 13,564 women were selected to complete the questionnaire. Because of the approximately equal sample sizes in each district, at the national level, the sample was not self-weighing. For results to be proportionate at the national level, the weighting factor has been added to the data file to yield a sample of 7856 women.[10] Information for anthropometry measurements and age from children (0-59 months) was collected with the parents/caregiver's consent to yield an analytical weighted sample of 3599 eligible under-five children which was used in this study.[10]

\section{Study variables}

The key outcome variable is the child's nutritional status which measured as stunted and not stunted. Key independent variables are household size and compositions and family planning status. (1) household size and compositions were measured through the sum-total of usual members of the household coded as $1-3,4-5,6-7,8+$ and the usual number of children under five years in household coded as 1, 2, $3+$ under-five children. (2) family planning status was measured through birth order coded as 1-2, $3-4,5+$; birth interval ranged from 9-17months, 18-27months, 2837 months, and 38+ months; 
fertility preference coded as unwanted/mistimed pregnancy and wanted/timed pregnancy; the number of children ever born ranged from 1-2, 3-4, 5-6, 7+ children, maternal exact age at childbirth, and unmet family planning.

The study explored the association of key independent variables and the dependent variables. The selection of the control variables was based on which frequently reported in studies and the context of Rwanda. These variables are grouped in mother's characteristics (wealth quintile, occupation, level of education marital status, and place of residence) and children characteristics (age, size at birth and sex and duration of breastfeeding).

\section{Data analysis}

Statistical software "STATA version 13 was used for analysis. To analyse data, the author started with the description of the key explanatory variables. Here, the key explanatory variables were cross-tabulated with a key dependent variable by using a twoway table with measures of the association including Chi-square $\left(\mathrm{X}^{2}\right)$ for categorical variables, and $\mathrm{t}$ test for continuous variables. Then, for better exploration of the influences of both household size and compositions and family planning status on stunting among under-five children, the author modelled the predicted probability of stunting using logistic regression models. Here, the author ran two models. In the first model, only key explanatory variables (household size and compositions and family planning status) were entered into the model and its association with stunting was estimated.

In the second model, both household size and composition and family planning status were entered into the model to estimate their together effect on stunting by controlling confounding variables. The following regression equation illustrates how the final model was estimated:

$Y=\beta 0+\beta 1 H_{i}+\beta 2 F_{i}+\beta 3 M_{i}+\beta 4 C_{i}+e$ Where $\mathrm{Y}$ is the odds of stunting (predicted outcome); $\beta 0$ is the odds of stunting when all covariates are zero (intercept); $\beta 1$ has estimated coefficients for Household size and compositions; $\mathrm{H}_{\mathrm{i}}$ is household size and compositions; $\beta 2$ is estimated coefficients for family planning status; $F_{i}$ is family planning status; $\beta 3$ has estimated coefficients for mother characteristics; $M_{i}$ is mother characteristics; $\beta 4$ is estimated coefficients for children characteristics; $\mathrm{C}_{\mathrm{i}}$ is children characteristics; e is an error term.

\section{Ethical considerations}

The permission to use the "Demographic and Health Survey" (DHS) dataset was obtained by registering online at the "Demographic and Health Survey 
(DHS)" website of ICF which provided technical assistance to the International's DHS Program as part of its contract with the "United States Agency for International Development" (USAID). Then, dataSet Rwanda DHS 2014-2015 was provided to the researcher for its secondary data analysis. Also, throughout the world, in all DHS surveys, ethical considerations are well addressed.[10] The Rwanda DHS 2014-15 is the fifth survey of this type in Rwanda. It followed the standard of previous Rwanda DHS done in 1992, 2000, 2005, and 2010. The Rwanda DHS 2014-15 was executed by the "National Institute of Statistics of Rwanda" (NISR) in close cooperation with the Ministry of Health and the Rwandan Biomedical Center (RBC) under the direction of a steering committee.[10]

Table 1a. Children and mothers`'Socio-demographic characteristics

\begin{tabular}{|c|c|c|c|}
\hline & stunted $\mathrm{n}(\%)$ & $\begin{array}{l}\text { not stunted } \\
\mathrm{n}(\%)\end{array}$ & Total $\mathrm{n}(\%)$ \\
\hline $\begin{array}{l}\text { age of the children } \\
\text { (mean months) } \\
\text { t-test }=6.904, p<0.001\end{array}$ & 30.74526 & 26.77389 & 28.28563 \\
\hline \multicolumn{4}{|l|}{ sex of the child } \\
\hline male & $785(42.66)$ & $1,055(57.34)$ & $1,840(100.00)$ \\
\hline female & $585(33.26)$ & $1,174(66.74)$ & 1,759 (100.00) \\
\hline Total & $1,370(38.07)$ & $2,229(61.93)$ & $3,599(100.00)$ \\
\hline \multicolumn{4}{|l|}{$\mathrm{Chi}^{2}(1)=33.744, \mathrm{p}<0.001$} \\
\hline \multicolumn{4}{|l|}{ size of child at birth } \\
\hline very large & $86(34.26)$ & $165(65.74)$ & $251(100.00)$ \\
\hline larger than average & $376(33.33)$ & $752(66.67)$ & $1,128(100.00)$ \\
\hline average & $628(37.54)$ & $1,045(62.46)$ & $1,673(100.00)$ \\
\hline smaller than average & $219(49.55)$ & $223(50.45)$ & $442(100.00)$ \\
\hline very small & $54(58.06)$ & $39(41.94)$ & $93(100.00)$ \\
\hline
\end{tabular}




$\begin{array}{llll}\text { don't know } & 5(55.56) & 4(44.44) & 9(100.00) \\ \text { Total } & 1,368(38.04) & 2,228(61.96) & 3,596(100.00)\end{array}$

Fisher's exact, $\mathrm{p}<0.001$

\begin{tabular}{llll}
\hline $\begin{array}{l}\text { breast feeding (mean } 57.65201 \\
\text { months) }\end{array}$ & 50.3143 & 53.10504 \\
t-test $=5.457, \mathrm{p}<0.001$ & & & \\
\hline $\begin{array}{l}\text { mother`s age (mean } 30.58613 \\
\text { years) }\end{array}$ & 30.17766 & 30.33315 \\
t-test $1.890, p<0.029$ & & & \\
\end{tabular}

$\mathrm{t}$-test $=1.890, \mathrm{p}<0.029$

\section{mother's marital status}

never in union

married

living with partner

widowed

divorced

no longer living together

Total

$\mathrm{Chi}^{2}(5)=23.202, \mathrm{p}<0.001$

$\begin{array}{lll}121(38.91) & 190(61.09) & 311(100.00) \\ 679(34.73) & 1,276(65.27) & 1,955(100.00) \\ 435(42.19) & 596(57.81) & 1,031(100.00) \\ 27(43.55) & 35(56.45) & 62(100.00) \\ 36(41.38) & 51(58.62) & 87(100.00) \\ 72(47.06) & 81(52.94) & 153(100.00) \\ 1,370(38.07) & 2,229(61.93) & 3,599(100.00)\end{array}$

\section{mother's occupation}

not working

professional/technical

Clerical

85(33.73)

167(66.27)

$252(100.00)$

$16(12.80)$

$109(87.20)$

125 (100.00)

Sales

$1(12.50)$

$7(87.50)$

$8(100.00)$

106(29.69)

251(70.31)

357 (100.00)

agricultural - self e

$879(40.45)$

agricultural - employ

196(44.44)

1,294(59.55)

$2,173(100.00)$

Household/domestic

13(40.63)

245(55.56)

441 (100.00)

Services

19 (27.54)

19(59.38)

$32(100.00)$

$50(72.46)$

$69(100.00)$

skilled manual

30(34.48)

$57(65.52)$

87 (100.00)

24(45.28)

29(54.72)

53 (100.00)

Total

$1,369(38.06)$

2,228(61.94)

3,597 (100.00)

Fisher's exact, $p<0.001$

\section{wealth index}

$\begin{array}{llll}\text { Poorest } & 432(49.04) & 449(50.96) & 881(100.00) \\ \text { Poorer } & 353(46.63) & 404(53.37) & 757(100.00) \\ \text { Middle } & 263(38.73) & 416(61.27) & 679(100.00) \\ \text { Richer } & 180(29.75) & 425(70.25) & 605(100.00) \\ \text { Richest } & 142(20.97) & 535(79.03) & 677(100.00) \\ \text { Total } & 1,370(38.07) & 2,229(61.93) & 3,599(100.00) \\ \text { Chí }^{2}(4)=170.267, \quad \mathrm{p}< & & \\ 0.001 & & & \\ \text { place of residence } & & & \\ \text { Urban } & 195(25.16) & 580(74.84) & 775(100.00)\end{array}$




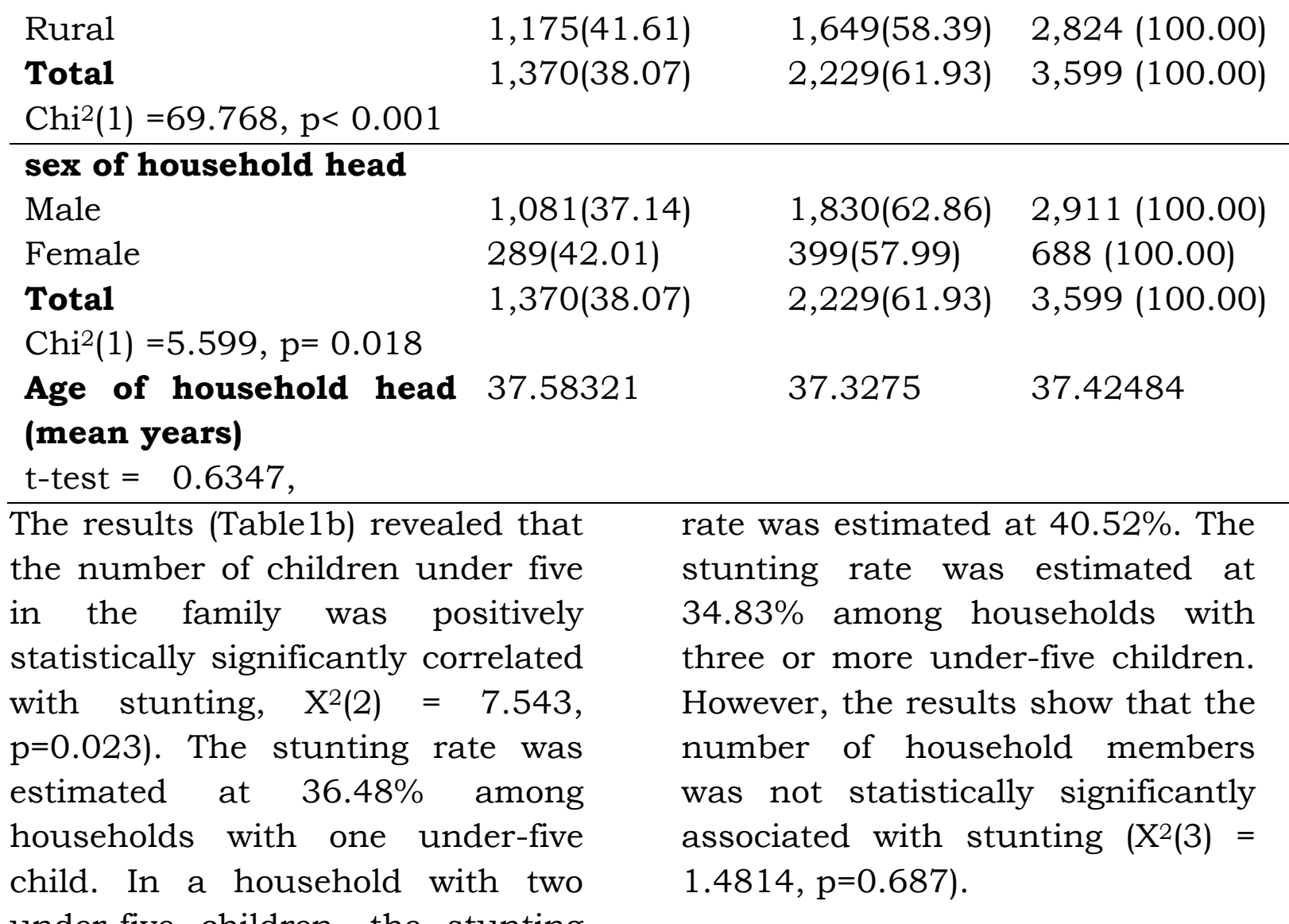

under-five children, the stunting

Table 1b. Household size and composition

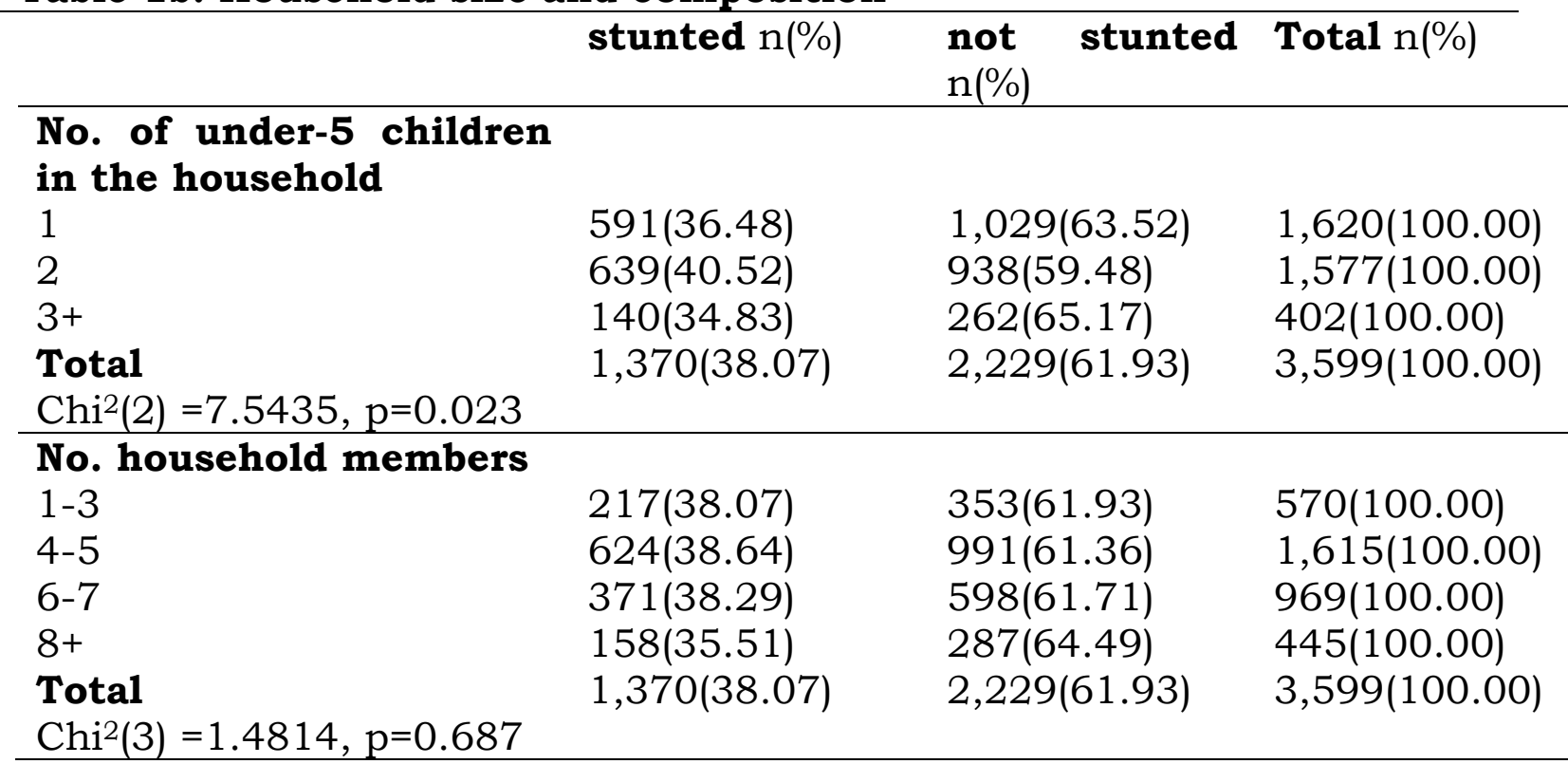

Regarding the patterns of family planning status, the results revealed that maternal age at birth was statistically significantly associated with stunting $\left(\mathrm{X}^{2}(2)=\right.$
13.183, $\mathrm{p}=0.001)$. The more mother's age at birth increases the more the stunting rate reduces. Among under-five children whose mother's age at birth ranged from 12-20years, the stunting rate was 
estimated at $42.51 \%$. The stunting rate was estimated at $36.15 \%$ among under-five children whose mother's age at birth ranged from 21-29years. The results also revealed that there is a statistically significant relationship between stunting and fertility preference (Fisher's exact, $\quad \mathrm{p}<0.001$ ). The stunting rate was estimated at $34.17 \%$ among under-five children whose mother needed more children, while the mother who reported no more need for children, the stunting rate was estimated at $42.53 \%$. The number of ever born children was also statistically significantly associated

\section{Table 1c. Family planning status by stunting}

\begin{tabular}{|c|c|c|c|}
\hline \multicolumn{4}{|c|}{ age of mother at birth } \\
\hline $12-20$ & $406(42.51)$ & $549(57.49)$ & $955(100.00)$ \\
\hline $21-29$ & $912(36.15)$ & $1,611(63.85)$ & $2,523(100.00)$ \\
\hline $30+$ & $52(42.98)$ & $69(57.02)$ & $121(100.00)$ \\
\hline Total & $1,370(38.07)$ & $2,229(61.93)$ & $3,599(100.00)$ \\
\hline \multicolumn{4}{|c|}{$\mathrm{Chi}^{2}(2)=13.183, \mathrm{p}=0.001$} \\
\hline \multicolumn{4}{|c|}{ fertility preference } \\
\hline needed more & $653(34.17)$ & $1,258(65.83)$ & $1,911(100.00)$ \\
\hline no more & $714(42.53)$ & $965(57.47)$ & $1,679(100.00)$ \\
\hline Do not know & $3(33.3)$ & $6(66.7)$ & $9(100.00)$ \\
\hline Total & $1,370(38.07)$ & $2,229(61.93)$ & $3,590(100.00)$ \\
\hline \multicolumn{4}{|c|}{ Fisher's exact, $p<0.001$} \\
\hline \multicolumn{4}{|c|}{ No of children ever born } \\
\hline $1-2$ & $570(34.34)$ & $1,090(65.66)$ & $1,660(100.00)$ \\
\hline $3-4$ & $455(40.55)$ & $667(59.45)$ & $1,122(100.00)$ \\
\hline $5-6$ & $204(41.30)$ & $290(58.70)$ & $494(100.00)$ \\
\hline $7+$ & $141(43.65)$ & $182(56.35)$ & $323(100.00)$ \\
\hline Total & $1,370(38.07)$ & $2,229(61.93)$ & $3,599(100.00)$ \\
\hline \multicolumn{4}{|c|}{$\mathrm{Chi}^{2}(3)=19.194, \mathrm{p}<0.001$} \\
\hline \multicolumn{4}{|l|}{ birth order } \\
\hline $1-2$ & $665(35.47)$ & $1,210(64.53)$ & $1,875(100.00)$ \\
\hline $3-4$ & $396(40.33)$ & $586(59.67)$ & $982(100.00)$ \\
\hline $5+$ & $309(41.64)$ & $433(58.36)$ & $742(100.00)$ \\
\hline Total & $1,370(38.07)$ & $2,229(61.93)$ & $3,599(100.00)$ \\
\hline $\mathrm{Chi}^{2}(2)=11.53$ & & & \\
\hline
\end{tabular}

with stunting $\left(\mathrm{X}^{2}(3) \quad=19.194\right.$, $\mathrm{p}<0.001)$. The results of this study show that the stunting rate decreases as the number of ever born children increases. This observation was also found for birth order. The birth order was also statistically significantly associated with stunting $\left(\mathrm{X}^{2}(2)\right.$ $=11.530, \mathrm{p}<0.003)$. The more birth order increases the more the stunting rate increases. Furthermore, the findings also show that unmet family planning $\left(\mathrm{X}^{2}(8)=24.052, \quad \mathrm{p}=0.002\right) \quad$ is statistically significantly correlated with stunting. 


\begin{tabular}{llll}
\hline birth interval/months & & & \\
$9-17$ & $43(36.75)$ & $74(63.25)$ & $117(100.00)$ \\
$18-27$ & $206(41.20)$ & $294(58.80)$ & $500(100.00)$ \\
$28-37$ & $264(40.87)$ & $382(59.13)$ & $646(100.00)$ \\
$38+$ & $499(37.55)$ & $830(62.45)$ & $1,329(100.00)$ \\
Don`t know & $358(35.55)$ & $649(64.45)$ & $1,007(100.00)$ \\
Total & $1,370(38.07)$ & $2,229(61.93)$ & $3,599(100.00)$ \\
Chi'(4) =7.1715, p=0.127 & & & \\
\hline unmet FP & & & \\
unmet need for spacing & $181(40.86)$ & $262(59.14)$ & $443(100.00)$ \\
unmet need for limiting & $113(42.16)$ & $155(57.84)$ & $268(100.00)$ \\
using for spacing & $341(34.58)$ & $645(65.42)$ & $986(100.00)$ \\
using for limiting & $333(42.80)$ & $445(57.20)$ & $778(100.00)$ \\
spacing failure & $29(33.72)$ & $57(66.28)$ & $86(100.00)$ \\
limiting failure & $12(31.58)$ & $26(68.42)$ & $38(100.00)$ \\
no unmet need & $189(33.10)$ & $382(66.90)$ & $571(100.00)$ \\
not married & $163(39.85)$ & $246(60.15)$ & $409(100.00)$ \\
infecund, menopausal & $8(44.44)$ & $10(55.56)$ & $18(100.00)$ \\
Total & $1,369(38.06)$ & $2,228(61.94)$ & $3,597(100.00)$ \\
Chi'2(8)=24.052, p = 0.002 & & & \\
\hline
\end{tabular}

To attain the study objective, the author tested whether the key explanatory variables (household size and compositions and family planning status) predict the outcome variable (stunting) through two models. In model1, there was no difference in stunting prediction between households with two under-five children and households with one under-five child $(p>0.05)$. However, the households with 3 under-five children or more increased their log odds of having stunted underfive child by 0.339 compared to families with one under-five child ( $p<0.05$, CI 95\%=0.055, 0.623). Besides, the results from model1 also show that mothers who reported no need for more children decrease their log odds of having stunted child by 0.342 compared to mothers who reported that they still need more children $(\mathrm{p}<.001$, CI95\%=-0.505, -0.179). However, regarding the sum-total of ever born children, model1 shows that as the sum-total of ever born children increases, the log odds of having a stunted child decrease. Furthermore, unmet family planning also significantly predicts the stunting among under-five children as not unmet need decreases the log odds of having stunted child by 0.3338 compared to unmet family planning for spacing $\quad(\mathrm{p}<0.05, \quad \mathrm{CI} 95 \%=0.0764$, 0.591).

The overall model (model2) examines whether family planning status together with household size and compositions predicts stunting among under-five 
children by controlling mothers' and children's characteristics. Mothers who give birth at 30 years old and above decreases their log odds of having stunted under-five children by 0.682 compared to mothers who gave birth to 1219years old $(\mathrm{p}<0.05,95 \% \mathrm{CI}=$ $1.222,-1.141)$. For mothers who reported the no need for more children had decreased log odds of having stunted under-five children by 0.296 compared with mothers who reported the need for more children $(\mathrm{p}<0.05$, CI95\%=-0.549, 0.042). Model2 shows that the prediction of stunting by the sumtotal of ever born children, birth order, and the birth interval is not statistically significant $(p>0.05)$.
Besides, in the overall model (model2), there was no difference in stunting prediction between households with two under-five children and household with one under-five child ( $p>0.05)$, while the households with 3 under-five children or more had increased log odds of having stunted under-five child by 0.373 compared with families with one under-five child $(\mathrm{p}<0.05, \quad 95 \% \mathrm{CI}=0.057, \quad 0.689)$. Furthermore, the results of model2 show that not unmet family planning need increases the log odds of having a stunted child by 0.297 compared to the unmet need for spacing $(\mathrm{p}<0.05, \quad 95 \%$ $\mathrm{CI}=0.0193,0.574)$.

Table 2. Estimates for logistic regression predicting the probability of stunting change by household size and composition and family planning status

\begin{tabular}{llll} 
Model1 & log & $\begin{array}{l}\text { Mode12 } \\
\text { odds(95\%CI) }\end{array}$ & $\log$ \\
\hline
\end{tabular}

No. of under-5 children in the household

0.under-5 number $\{0=1$ child $\}$

1.under-5 number $\{1=2$ children $\}$

$-0.147[-0.314,0.019]$

$-0.124[-0.306,0.0582]$

2.under-5 number $\{2=3+$ children $\}$

$0.339 *[0.0553,0.623]$

$0.373 *[0.0577,0.689]$

\section{No. household members}

0.household members $\{0=1-3\}$

1.household members $\{1=4-5\}$

2.household members $\{2=6-7\}$

$0.149[-0.077,0.375]$

$0.0450[-0.212,0.302]$

3.household members $\{3=8+\}$

$0.352^{* *}[0.089,0.614]$

$0.0645[-0.255,0.384]$

$0.560^{* * *}[0.238,0.881]$

$0.0445[-0.358,0.447]$

\section{Age of mother at birth (years)}

0 .age of the mother at birth $\{0=12$

20)

1.age of the mother at birth $\left\{1=21-0.254^{* *}[0.0975,0.410] \quad 0.0599[-0.139,0.258]\right.$ 
$29\}$

2.age of the mother at birth $\{2=30+\}$

$-0.126[-0.518,0.267]$

$-0.682^{*}[-1.222,-0.141]$

\section{Fertility preference}

0. fertility preference $\{0=$ need more $\}$

1.fertility preference $\{1=$ no more $\}$

$$
-0.342^{* * *}[-0.505,-0.179] \quad-0.296^{*}[-0.549,0.0427]
$$

\section{No of children ever born}

0. No of children ever born $\{0=1-2\}$

1. No of children ever born $\{1=3-4\}$

$-0.569^{* * *}[-0.899,-0.239] \quad-0.225[-0.593,0.143]$

2.No of children ever born $\{2=5-6\}$

$-0.990^{* *}[-1.594,-0.387] \quad-0.324[-1.002,0.354]$

3. No of children ever born $\{3=7+\}$

$-1.176^{* * *}[-1.857,-0.495] \quad-0.441[-1.217,0.335]$

\section{Table 2: Cont.}

\section{Model1 log odds(95\%CI) Model2 log} odds(95\%CI)

\section{Birth order}

0. birth order $\{0=1-2\}$

1.birth order $\{1=3-4\}$

$0.227[-0.0934,0.547]$

$-0.106[-0.465,0.252]$

2. birth order $\{2=5+\}$

$0.593[-0.0166,1.203]$

$-0.0670[-0.759,0.625]$

\section{Birth interval (months)}

0.birth interval $\{0=9-17\}$

1.birth interval $\{1=18-27\}$

$-0.164[-0.587,0.260]$

$-0.200[-0.644,0.244]$

2.birth interval $\{2=28-37\}$

$-0.0992[-0.516,0.318]$

$-0.102[-0.541,0.338]$

3. birth interval $\{3=38+\}$

$0.0996[-0.309,0.508]$

$-0.0383[-0.475,0.399]$

4.birth interval $\left\{4=\right.$ don ${ }^{\top}$ know $\}$

$-0.191[-0.616,0.235]$

$-0.0475[-0.499,0.404]$

\section{Unmet need FP}

0.unmet need $\{0=$ spacing $\}$

1.unmet need $\{1=$ limiting

2.unmet need $\{2=$ using for spacing

$-0.0538[-0.361,0.253]$

$0.2675 *[0.037,0.497]$

$0.264[-0.104,0.633]$

3.unmet need $\{3=$ using for limiting\}

$-0.0799[-0.316,0.156]$

$0.0985[-0.169,0.366]$

4.unmet need $\{4=$ spacing failure $\}$

$0.3059[-0.179,0.971]$

$0.149[-0.153,0.452]$

5 .unmet need $\{5=$ limiting failure $\}$

$0.4033[-0.306,1.113]$

$0.355[-0.164,0.874]$

$6 . u n m e t$ need $\{6=$ not unmet need $\}$

$0.3338^{*}[0.0764,0.591]$

$0.695[-0.0787,1.470]$

7.unmet need $\{7=$ not married and no sex 0.0417 [-0.232, 0.315$]$

$0.297^{*}[0.0193,0.574]$

in last 30 days\}

8.unmet need $\{8=\quad$ infecundity, $-0.1467[-1.095,0.802$

$0.339[-0.0936,0.772]$

menopausal\}

$0.229[-0.786,1.244]$ 


\section{Mother characteristics}

Mother's current age (years)

$0.0116[-0.014,0.037]$

Age of household head (Years)

$0.00532[-0.002,0.013]$

\section{Sex of household}

0. sex of household head $\{0=$ male $\}$

1 . sex of household head $\{1=$ female $\}$

$0.0266[-0.218,0.271]$

\section{Wealth index}

0. wealth index $\{0=$ poorest $\}$

1 .wealth index $\{1=$ poor $\}$

$0.0644[-0.146,0.275]$

2.wealth index $\{2=$ middle $\}$

$0.378^{* * *}[0.154,0.602]$

3.wealth index $\{3=$ rich $\}$

$0.737^{* * *}[0.488,0.985]$

4.wealth index $\{4=$ richest $\}$

$0.911^{* * *}[0.581,1.241]$

\section{Place of residence}

0. place of residence $\{0=u r b a n\}$

1. place of residence $\{1=$ rural $\}$

\section{Educational level}

0 . educational level $\{0=$ no education $\}$

1. educational level $\{1=$ primary $\}$

$0.00482[-0.206,0.216]$

2. educational level $\{2=$ secondary $\}$

$0.344[-0.0039,0.692]$

3 . educational level $\{3=$ higher $\}$

$1.297^{* *}[0.350,2.243]$

\section{Marital status}

0. marital status $\{0=$ never in union $\}$

1. marital status $\{1=$ married $\}$

2. marital status $\{2=$ living with partner $\}$

$0.461 *[0.0107,0.910]$

3. marital status $\{3=$ widowed $\}$

$0.221[-0.225,0.667]$

4. marital status $\{4=$ divorced $\}$

$0.275[-0.367,0.918]$

5. marital status $\{5=$ separated $\}$

$0.348[-0.187,0.884]$

$0.0256[-0.401,0.453]$ 


\section{Table 2. Cont.}

Model1 log odds(95\%CI) Model $2 \log$

odds $(95 \% \mathrm{CI})$

\section{Occupation}

0. occupation $\{0=$ not working $\}$

1. occupation $\{1=$ professional $\}$

$0.375[-0.300,1.051]$

2. occupation $\{2=$ clerical $\}$

$0.127[-2.061,2.315]$

3. occupation $\{3=$ sales $\}$

$0.166[-0.212,0.544]$

4. occupation $\{4=$ agricultural - self-

$0.227[-0.0911,0.546]$

employed\}

5. occupation $\{5=$ agricultural -

$0.402 *[0.0334,0.771]$

employee\}

6. occupation $\{6=$ household and

$-0.456[-1.280,0.367]$

domestic\}

7. occupation $\{7=$ services $\}$

8. occupation $\{8=$ skilled manual $\}$

9. occupation $\{9=$ unskilled manual $\}$

$-0.131[-0.757,0.494]$

$0.146[-0.421,0.712]$

$-0.254[-0.913,0.405]$

Child's age in months

$-0.0109 *[-0.019,-0.002]$

sex of child

0. sex of child $\{0=$ male $\}$

1 . sex of child $\{1=$ female $\}$

$0.457^{* * *}[0.312,0.60]$

\section{Size of a child at birth}

0. size at birth $\{0=$ very large $\}$

1 .size at birth $\{1=$ larger than average

2 . size at birth $\{2=$ average $\}$

3 .size of a child at birth $\{3=$ smaller

$-0.173[-0.468,0.122]$

than average $\}$

4. size at birth $\{4=$ very small $\}$

$-0.686^{* * *}[-1.026,-0.347]$

5 .size at birth $\{5=$ do not know $\}$

$-1.007^{* * *}[-1.529,-0.485]$

Constant

$0.572 *[0.114,1.029]$

$-0.632[-2.023,0.759]$

$95 \%$ confidence intervals in brackets

${ }^{*} p<0.05,{ }^{* *} p<0.01,{ }^{* * *} p<0.001$ 


\section{Discussion}

By conducting this study, my main concern was to examine the relationship between both household size and composition and family planning status and stunting among under-five children in Rwanda. After controlling the confounding variables, the findings reveal that stunting is high in households with more than three under-five children compared to households with one under-five child. However, although the literature suggests that high rate of stunting identified in families with a large number of usual members compared to those with a small number of usual members, surprisingly, the findings in this study reveal that households with a large number of usual members were as likely as households with a small number of usual members to have stunted under-five children. This important finding challenges the assumption that the availability of food for larger households is not frequently higher than in smaller households and this contrast reflects the rate of children's growth.[9] However, this can be applied in the Rwandan context were during the war that started in the early 1990s and ended in Genocide in 1994, the social and family cohesion was destroyed. Rwanda is still recovering from the consequences of this. This is consistent with reports and findings of studies showing evidence of lack of social support for new families, poverty, a high rate of unintended pregnancies among youth, and a high rate of illegal marriage at an early age.[16-19] All of these may be among other factors that could explain this situation in the Rwandan context.

Next, the second question was to know whether family planning status associated with stunting among children under five in Rwanda. By examining the question, results revealed that stunting rates of children under five are different for age categories of the mother at childbirth. After the control of relevant variables, stunting among under-five children is lower when age at birth is thirty years old or more compared to when age at birth is lower than thirty years. These results are consistent with the hypothesis that the risk of stunting decreases with the age of the mother at childbirth.[14] Similar results have been found in the previous researches, $[20,21]$ that age at birth has a relationship with malnutrition among children under five, even after adjustment of possible confounders. However, in the Rwandan context, this can have another perspective as stipulated in reproductive and health policy, the legal age for marriage is 21 years old. In this regard, the result from Rwanda DHS estimated the mean marriage age at 21.9 years.[10] Besides, 
Rwandan women are having their first birth nearly one year after their marriage.[10]

The disparity of stunting among under-five children could not only be explained by maternal age at birth but also other factors such as fertility preference as was revealed by the results of this study. The results of this study show that stunting was lower among children under five from the mothers who have no more need for kids compared to mothers with the need for more kids. Even after the control of relevant confounders. These findings lead one to wonder what motivates the mother to continue having an increased need for more children unless the poor health status of their children. One of the interpretation as the researcher mentioned above is the importance the Rwandan society gives to a child. However, the literature has shown that the quality of care in the family with many siblings is affected by the limited time the mother has to devote to the caring of each child.[20] additionally, breastfeeding of the youngest child is frequently compromised, while older childcare may be lacking, leading to malnutrition.[22]

However, by continuing to explore the link between family planning status and stunting among children under five in Rwandan, it was also surprising to find that there is no difference in stunting among under-five children by birth order, by the total of children in the household and birth interval after controlling the relevant confounders. More fundamental still, these results are not consistent with the assumption that increased birth order leads to the risk for a child to have stunting.[3] However, the comprehension of the correlation between a child's nutritional status and birth order is very significant in the context of Rwanda. A thinkable interpretation about this finding could be that the hypothesis of a lower sibling is probably to be unwanted leading to less care and attention from parents may not be applied in the context of Rwandan married women (most of the sample) where every child is considered as wanted, perhaps untimely pregnancy.

Therefore, given the same importance is given to everyone in the family, except for some individual effect, all children are exposed to the same extent. Instead, the reason could be the distribution of food and resources within the household reduces with increased sum-total births in the family.[23] Besides, family planning might affect the nutrition status of the studied children. In this regard, the results also show that unmet family planning significantly predicts stunting. Therefore, the evidence is that for proper amelioration of mothers 
health and their children, births have to be well spaced[22,24]. Not only that family planning will help mothers to avoid undesired and high-risk pregnancies but also to have babies that are not too young or to have too many which may compromise the mothers health leading to poor nutritional results for their babies. [25]

Like other scientific research, a few limitations to this study must be considered. In this study, a crosssectional design was used to examining the influences of household size and composition and family planning status on stunting among under-five children. Consequently, there is an inability to establish a causal relationship between these factors. However, the results provide important information regarding the influences of household size and composition and family planning status on stunting among children under five in Rwanda. Further methodological aspect such as the mixed-method is required to examine the possible mechanisms moderate the correlation between family planning status family and household size and composition and stunting among under-five children in Rwanda.

\section{Conclusion}

The findings of this study suggest a significant association between stunting and family planning and household size and composition. This includes the statistically significant association between stunting and the sum-total of children under five in the household, maternal age at childbirth, fertility preference, and unmet need for family planning. This baseline information on the effect of household size and composition and family planning status on stunting among children under five in Rwanda could be utilized by partners in the field of healthcare to prepare the interventions based on evidence for programs of nutrition and to initiate activities for community sensitization regarding the prevention of stunting. This study could contribute to the set of knowledge that might be desired by some researchers and maybe the basis or reference for other scientific research for those who want to involve their research in correlates of household size and composition and family planning status with the undernutrition among children under five in countries with the similar context of Rwanda.

\section{Authors' contributions}

JBB designed the full protocol of the study. The same author collected, analyzed, and interpreted data and wrote the manuscript. 


\section{Competing interests}

The author declares that there are no competing interests.

This article is published open access under the Creative Commons AttributionNonCommercial NoDerivatives (CC BYNCND4.0). People can copy and redistribute the article only for noncommercial purposes and as long as they give appropriate credit to the authors. They cannot distribute any modified material obtained by remixing, transforming or building upon this article. See https:/ / creativecommons.org/licenses/by-ncnd/4.0/

\section{References}

1. UNICEF, WHO, Group WB. Levels and Trends in Child Malnutrition [Internet]. Jt. Child Malnutrition Estim. Geneva, Switzerland; 2017. Available from: http:/ / www.who.int/nutgrowt hdb/jme_brochoure2017.pdf

2. Bogale TY, Bala ET, Tadesse M, Asamoah BO. Prevalence and associated factors for stunting among 6-12 years old school-age children from the rural community of Humbo district, Southern Ethiopia. BMC Public Health. BMC Public Health; 2018;18:1-8.

3. Rahman M. Association between the order of birth and chronic malnutrition of children: a study of nationally representative Bangladeshi sample. Cad Saude Publica. 2016;32:1-
4. Shapiro-Mendoza C, Selwyn BJ, Smith DP, Sanderson M. Parental pregnancy intention and early childhood stunting: Findings from Bolivia. Int $J$ Epidemiol. 2005;34:387-96.

5. Rawe K, Jayasinghe D, Mason F, Davis A, Pizzini M, Garde $\mathrm{M}$, et al. A Life Free From Hunger [Internet]. London, UK; 2012. Available from: https://resourcecentre.saveth echildren.net/library/life-freehunger-tackling-childmalnutrition

6. Souza AP, Ponczek V. New Evidence of the Causal Effect of Family Size on Child Quality. $J$ Hum Resour. 2012;54:122-70.

7. Juhn C, Rubinstein Y, Zuppann CA. The quantityquality trade-off and the formation of cognitive and non-cognitive skills [Internet]. NBER Work. Pap. Ser. Cambridge; 2015. Available from:

http: / /www.nber.org/papers / w2 1824

8. Khan M. Effects of Birth Order on Child Nutritional Status [Internet]. Lahole School of Economics; 2014. Available from: http://121.52.153.178:8080/ xmlui/bitstream/handle/ 123 456789/14051/upload-MPhil Thesis 2014 - Maha Khan.pdf?sequence $=1$ \&isAllo wed $=\mathrm{y}$ 
9. Dasgupta K, T-Solomon K. Family Size Effects on Child Health: Evidence on the Quantity-Quality Trade-off using the NLSY [Internet]. Work. Cent. Soc. Data Anal. 2017. Report No.: 2017-04. Available from: https://ideas.repec.org/p/aut /wpaper/201704.html

10. National Institute of Statistics of Rwanda. 2014-15 Demographic and Health Survey Key Findings [Internet]. Kigali; 2015. Available from: http://www.statistics.gov.rw / publication/demographicand-health-survey-20142015final-report

11. Menon, P., Ruel, M.T. \& Morris S. Socio-economic differentials in child stunting are considerably larger in urban than rural areas: analysis of 10 DHS data sets. Food Nutr Bull. 2000;21:2829.

12. UN. World Fertility Patterns 2015 [Internet]. Data Book. New York; 2015. Available from:

https://www.un.org/en/devel opment/desa/population/pub lications/pdf/fertility/worldfertility-patterns-2015.pdf

13. Fink G, Sudfeld CR, Danaei G, Ezzati M, Fawzi WW. Scaling-up access to family planning may improve linear growth and child development in low and middle-income countries. PLoS One. 2014;9:1-9.

14. Winter $\mathrm{R}$ and Rutstein S. Contraception Needed to Avoid High-Fertility-Risk Births, and Maternal and Child Deaths That Would Be Averted [Internet]. Rockville, Maryland, USA; 2015. Available from: https://dhsprogram.com/pub s/pdf/AS50/AS50.pdf

15. Sphere Project. Humanitarian Charter and Minimum Standards in Humanitarian Response [Internet]. Third edit. Phil Greaney, Sue Pfiffner DW, editor. Bourton, UK: Sphere Project; 2011. Available from: https: / / www.unhcr.org/uk/5 Ob491b09.pdf

16. Institute of Research and Dialogue for Peace. Healing our Community - Promoting Social Cohesion in Rwanda [Internet]. 2017 [cited 2018 Mar 22]. Available from: http://www.irdp.rw/2017/09 /11/healing-our-communitypromoting-social-cohesion-inrwandal

17. Brian Corry. Policy Framework for Social Cohesion [Internet]. Kigali; 2012. Available from: https://opendocs.ids.ac.uk/op endocs/bitstream/handle/20. 500.12413/9646/Policies for Social 
Cohesion.pdf;sequence $=1$

18. World Bank. Rwanda economic update, February 2016: Rwanda at work [Internet]. Kigali; 2016. Available from: https://openknowledge.world bank.org/handle/10986/2402 3

19. Nsanzimana J-C. Marriages and divorces in Rwandanumbers vs comments [Internet]. WordPress.com. 2012 [cited 2018 Mar 22]. Available from: https://sjcgroup7.wordpress. $\mathrm{com} /$ marriages-and-divorcesin-rwanda-numbers-vscomments /

20. Ajao KO, Ojofeitimi EO, Adebayo AA FA and AO. Influence of Family Size, Household Food Security Status, and Child Care Practices on the Nutritional Status of Under-five. Afr $J$ Reprod Health. 2010;14:12332.

21. Black RE, Allen LH, Bhutta ZA, Caulfield LE, de Onis M, Ezzati M, et al. Maternal and child undernutrition: global and regional exposures and health consequences. Lancet. 2008;371:243-60.

22. Owoaje E, Onifade O, Desmennu A. Family and socioeconomic risk factors for undernutrition among children aged 6 to 23 months in Ibadan, Nigeria. Pan Afr Med J. 2014;17:1-7.

23. Menon P, Ruel MT. SocioEconomic Differentials in Child Stunting are Consistently Larger in Urban than in Rural Areas [Internet]. Washington, D.C; 2000. Report No.: 97. Available from:

http://ebrary.ifpri.org/utils/g etfile/collection/p15738coll2/ id/ 125427 / filename/ 125428 . pdf

24. Akombi BJ, Agho KE, Hall JJ, Merom D, Astell-Burt T, Renzaho AMN. Stunting and severe stunting among children under-5 years in Nigeria: A multilevel analysis. BMC Pediatr [Internet]. BMC Pediatrics; $\quad 2017 ; 17: 1-16$. Available from: http:/ /dx.doi.org/10.1186/s1 2887-016-0770-Z

25. Smith $R$ and Naik R. family planning improves nutrition evidence from studies in lowand middle-income countries. Health Policy Project [Internet]. Washington, DC; 2015. Available from: https://www.healthpolicyproj ect.com/pubs/691_FPandNut ritionBrief.pdf 